\title{
Does lidocaine gel produce an effective analgesia prior to copper IUD insertion? Randomized clinical trial
}

\author{
Ahmed M. Abbas ${ }^{1 *}$, Ebtehal Ragab ${ }^{1}$, Shymaa S. Ali ${ }^{1}$, Nahla W. Shady ${ }^{2}$, \\ Hany F. Sallam ${ }^{2}$, Ali M. Sabra ${ }^{1}$
}

${ }^{1}$ Department of Obstetrics and Gynecology, Faculty of Medicine, Assiut University, Assiut, Egypt
${ }^{2}$ Department of Obstetrics and Gynecology, Faculty of Medicine, Aswan University, Aswan, Egypt

Received: 20 December 2017

Accepted: 24 January 2018

*Correspondence:

Dr. Ahmed M. Abbas,

E-mail: bmr90@hotmail.com

Copyright: (c) the author(s), publisher and licensee Medip Academy. This is an open-access article distributed under the terms of the Creative Commons Attribution Non-Commercial License, which permits unrestricted non-commercial use, distribution, and reproduction in any medium, provided the original work is properly cited.

\begin{abstract}
Background: IUD is a small contraceptive device, often containing either copper or levonorgestrel, which is inserted into the uterus. Objective of present study was to determine if lidocaine gel prior to intrauterine device (IUD) insertion decreases pain with the insertion procedure among multiparous women choosing the copper T380A-IUD.

Methods: It is a randomized double-blind controlled trial carried out at Assiut Women's Health Hospital, Assiut, Egypt. Parous women eligible for Copper IUD insertion attended the Family Planning Clinic were recruited and randomized in a 1:1 ratio to lidocaine gel or placebo. Two $\mathrm{ml}$ of the study medications were topically placed on the cervix 3 minutes before IUD insertion. The primary outcome was the difference in pain scores using a 10-cm Visual Analogue Scale (VAS) during IUD insertion. We considered a $1.5 \mathrm{~cm}$ difference in VAS scores between study groups as clinically significant.

Results: One hundred women consented to participate and randomized either to group I: lidocaine group or group II: placebo group. Both groups were homogenous in baseline socio-demographic data. There was significant difference in mean pain scores for IUD placement between women who received lidocaine gel and placebo at two steps of insertion (at vulsellum application and at uterine sounding) while the rest of steps show no statistical significant difference $(p=0.000)$. There were no statistical significant differences between both group as regard the ease of insertion, the duration of insertion and the satisfaction score after the procedure $(p>0.05)$.

Conclusions: This study depicts that the use of lidocaine gel prior to copper IUD insertion in multiparous women could partially reduce the pain during tenaculum placement and uterine sounding.
\end{abstract}

Keywords: Contraception, Intrauterine device, Lidocaine, Pain relief

\section{INTRODUCTION}

IUD is a small contraceptive device, often containing either copper or levonorgestrel, which is inserted into the uterus. They are one form of long-acting reversible contraception (LARC) which is the most effective types of reversible birth control. ${ }^{1}$ Depending on the country, the use of IUDs worldwide ranges from $2 \%$ to $75 \%$. On average, $15 \%$ of reproductive-aged women in developing regions and $9 \%$ in developed regions use IUDs. ${ }^{2}$ IUDs are considered appropriate for most women, including nulliparous women and adolescents. ${ }^{3}$

Many studies were published about the use of different medications or technical modifications in the insertion procedure trying to minimize the pain during IUD insertion. ${ }^{4}$ These include non-steroid anti-inflammatory drugs (NSAIDs), misoprostol for pre-insertion cervical ripening, nitric oxide donors, and local anesthetics. ${ }^{5-10}$ 
Technical modifications were also published in order to omit or modify some steps during the insertion to decrease the participants' pain perception. ${ }^{11-14}$

The levels of pain that women experience during IUD insertion vary in published reports. Most women experience mild to moderate discomfort during IUD insertion. Rarely, the pain is severe and associated with nausea and weakness. ${ }^{6}$ Predictors of pain during IUC insertion include nulliparity, age greater than 30 years, a longer interval since last pregnancy or menses, history of dysmenorrhea, and not currently breastfeeding. ${ }^{6}$

Lidocaine gel is routinely used in the distal urethra prior to Foley catheter placement, as well as in the nasal canal prior to nasogastric or nasotracheal tube placement. In each of these cases lidocaine gel has been shown to decrease pain scores associated with insertion. ${ }^{15}$ The endocervical canal is lined with columnar epithelium as is the nasal canal. The ecto-cervix and distal urethra share stratified squamous epithelium lending biologic plausibility to this intervention for both tenaculum placement to the ectocervix as well as IUD insertion.

Therefore, the current study aims to evaluate the analgesic effect of topical lidocaine gel placed on the cervix prior to IUD insertion.

\section{METHODS}

The current study was a randomized, double-blind trial. The study was conducted Assiut Women Health Hospital, Egypt between October 2016 and March 2017. The Institutional Ethical Review Board approved the study, and we obtained a written informed consent from all participants before enrollment.

A total of 100 women attending the family planning outpatient clinic seeking IUD for contraception were invited to participate in our study. We included in our study women aged (18-50 years) not taken analgesics or anxiolytics in the 24 hours prior insertion and not taken misoprostol prior to insertion.

A statistician, not otherwise involved in the study, prepared a computer generated random table and placed the allocation data in sequentially numbered opaque sealed envelopes. Each envelope had a card noting the group identifier inside. A single pharmacist was responsible packaging of both gels in sterile tubes with labeling them as A and B. Only the Pharmacist knew what the medication in tube A and B was, so neither the clinician nor the women knew the type of the preparation.

The participated women were entered the screening phase of the study. This phase included history taking (about age, parity, mode of previous delivery, pattern of menstrual cycle, history of pelvic surgery, sexually transmitted diseases, interval from last pregnancy or last menses or last miscarriage and whether they had taken any pain or anxiety medications that day).

Before insertion, one of the study researchers explained the standard $10-\mathrm{cm}$ visual analog scale (VAS) to the participants for pain scoring. ${ }^{16}$ The severity of pain was assessed with VAS (with $0=$ no pain and $10=$ worst imaginable pain). Each woman received a copper T380A IUD (Pregna®T380A; Pregna International Ltd USA, Mumbai, India) for insertion.

The eligible women were allocated to either group I (lidocaine group) $1 \mathrm{~mL}$ lidocaine gel was placed on the cervix at the anterior lip and $1 \mathrm{~mL}$ in the cervix up to the level of the internal os using cotton swab or group II (placebo group) with an inert gel similar in appearance, color and consistency. The placebo cream was manufactured in the Department of PharmaceuticalsFaculty of Pharmacy. After a three-minute waiting period, the IUD was inserted in the standard fashion.

The IUD was inserted by one of the study investigators. Firstly, the speculum was placed into the vagina and the cervix was cleansed with Povidone iodine. Then, traction was applied on the cervix using tenaculum and the uterine sound was introduced followed by the IUD insertion. Immediate complications as uterine perforation and vasovagal attack in addition to the duration of insertion were recorded. A research assistant asked the women to rate the intensity of pain at five consecutive steps; at speculum placement, at tenaculum placement, at sound insertion, at IUD insertion and 5 minutes after the end of insertion using the same 10-point VAS.

After the end of procedure, the clinician assessed the ease of IUD insertion using the ease of insertion score (ES). The ES is a graduated VAS-like scale from zero to 10; in which 10 means terribly difficult insertion and zero means very easy insertion.

At 15 minutes post insertion; all women were asked to report their level of satisfaction with IUD insertion by completing a $10-\mathrm{cm}$ VAS (with $0=$ no satisfaction and $10=$ maximum satisfaction).

The primary outcome was the difference in mean pain VAS scores during IUD insertion. The secondary outcomes included the mean pain scores during speculum, tenaculum placement, sound insertion and 5 minutes post-insertion, the ease of insertion score, the women's satisfaction score and the duration of insertion

\section{Statistical analysis}

The data were collected and entered into a Microsoft Access database and were analyzed using the Statistical Package for Social Science (SPSS Inc., Chicago, version 21). The demographic characteristics and baseline data were compared between the groups. The outcome variables were calculated using Student's t test. For 
dichotomous variables, chi-square was used to estimate the significance value. For analysis, $p<0.05$ was considered to be significant.

\section{RESULTS}

One hundred and twenty women were counselled for participation, however; 20 women were excluded (8 patients were not willing to share in the RCT and 12 women did not meet the inclusion criteria).

One hundred women consented to participate and randomized either to group I: lidocaine group or group II: placebo group. Both groups were homogenous in baseline socio-demographic data without significant differences (Table 1).

Table 1: Socio-demographic criteria of the study participants.

\begin{tabular}{|c|c|c|c|}
\hline & $\begin{array}{l}\text { Lidocaine } \\
\text { group }(n=50)\end{array}$ & $\begin{array}{l}\text { Placebo } \\
\text { group }(n=50)\end{array}$ & $\begin{array}{l}P \text { - } \\
\text { value }\end{array}$ \\
\hline \multicolumn{4}{|l|}{ Age } \\
\hline Mean \pm SD & $30.58 \pm 5.28$ & $30.00 \pm 7.76$ & 0.747 \\
\hline \multicolumn{4}{|l|}{ Parity } \\
\hline Mean \pm SD & $2.72 \pm 0.86$ & $2.56 \pm 1.30$ & 0.371 \\
\hline \multicolumn{4}{|l|}{ Residency } \\
\hline Urban & $28(56 \%)$ & $29(58 \%)$ & \multirow{2}{*}{0.316} \\
\hline Rural & $22(44 \%)$ & $21(42 \%)$ & \\
\hline \multicolumn{4}{|c|}{ Previous VD } \\
\hline Yes & $37(74 \%)$ & $38(76 \%)$ & \multirow{2}{*}{0.649} \\
\hline No & $13(26 \%)$ & $12(24 \%)$ & \\
\hline \multicolumn{4}{|c|}{ Previous CS } \\
\hline Yes & $28(58 \%)$ & $25(50 \%)$ & \multirow{2}{*}{0.705} \\
\hline No & $22(44 \%)$ & $25(50 \%)$ & \\
\hline \multicolumn{4}{|c|}{ Previous miscarriage } \\
\hline Yes & $18(36 \%)$ & $12(24 \%)$ & \multirow{2}{*}{0.423} \\
\hline No & $32(64 \%)$ & $38(76 \%)$ & \\
\hline
\end{tabular}

SD; standard deviation, VD; vaginal delivery, CS; cesarean section

Table 2: Pain scores during IUD insertion in lidocaine and placebo groups.

\begin{tabular}{|llll|}
\hline & $\begin{array}{l}\text { Lidocaine } \\
\text { group } \\
(\mathrm{n}=50)\end{array}$ & $\begin{array}{l}\text { Placebo } \\
\text { group } \\
(\mathrm{n}=50)\end{array}$ & $\begin{array}{l}\text { P- } \\
\text { value }\end{array}$ \\
\hline $\begin{array}{l}\text { VAS speculum } \\
\text { insertion }\end{array}$ & $2.48 \pm 0.89$ & $2.42 \pm 0.84$ & 0.728 \\
\hline $\begin{array}{l}\text { VAS vulsellum } \\
\text { application }\end{array}$ & $3.62 \pm 1.14$ & $4.70 \pm 0.99$ & $0.000^{*}$ \\
\hline $\begin{array}{l}\text { VAS uterine } \\
\text { sounding }\end{array}$ & $3.78 \pm 1.25$ & $5.48 \pm 1.31$ & $0.000^{*}$ \\
\hline $\begin{array}{l}\text { VAS IUD insertion } \\
\text { VAS removal of } \\
\text { instruments }\end{array}$ & $5.06 \pm 0.92$ & $5.46 \pm 1.43$ & 0.241 \\
\hline $\begin{array}{l}\text { VAS 5 min post } \\
\text { procedure }\end{array}$ & $2.14 \pm 0.67$ & $2.28 \pm 0.73$ & 0.320 \\
\hline $\begin{array}{l}\text { VAS; visual analog scale, IUD; intrauterine device; } \\
\text { significant difference }\end{array}$ & & $3.02 \pm 1.04$ & 0.232 \\
\hline
\end{tabular}

Table 2 shows the mean pain scores for both groups. Women in lidocaine group reported lower pain scores only during vulsellum placement $(3.62 \pm 1.14$ vs. $4.70 \pm 0.99, \mathrm{p}=0.000)$ than placebo group and during uterine sounding $(3.78 \pm 1.25$ vs. $5.48 \pm 1.31, \mathrm{p}=0.000)$. No statistical significant differences between both groups in other steps of IUD insertion.

Table 3: Secondary outcomes of the study.

\begin{tabular}{|llll|} 
& $\begin{array}{l}\text { Lidocaine } \\
\text { group } \\
(\mathbf{n = 5 0})\end{array}$ & $\begin{array}{l}\text { Placebo } \\
\text { group } \\
(\mathbf{n}=50)\end{array}$ & $\begin{array}{l}\text { P- } \\
\text { value }\end{array}$ \\
\hline $\begin{array}{l}\text { Ease of insertion } \\
\text { score }\end{array}$ & $6.42 \pm 1.99$ & $6.74 \pm 1.38$ & 0.242 \\
\hline $\begin{array}{l}\text { Duration of } \\
\text { insertion (min) }\end{array}$ & $6.86 \pm 1.23$ & $6.82 \pm 1.55$ & 0.125 \\
\hline Satisfaction score & $4.72 \pm 0.45$ & $4.82 \pm 0.39$ & 0.979 \\
\hline Failure of insertion & 0 & 0 & ---- \\
\hline Perforation & 0 & 0 & ---- \\
\hline
\end{tabular}

The mean satisfaction scores were $4.72 \pm 0.45$ and $4.82 \pm 0.39$ in the lidocaine and placebo groups respectively $(\mathrm{p}=0.979)$. Additionally, no difference in the ease of insertion score was observed among both groups $(p=0.242)$. Additionally, the duration of IUD insertion was similar in both groups $(\mathrm{p}=0.125)$. No cases of uterine perforation or vasovagal reactions were observed in both groups (Table 3).

\section{DISCUSSION}

Pain during IUD insertion is multifactorial; application of the tenaculum on the cervical lip can induce severe pain. In addition, insertion of sound and IUD inside the uterine cavity can add to pain perception. ${ }^{17}$ Transmission of pain from the uterus occurs through two different visceral pain pathways: parasympathetic (S2-S4) provides sensory innervation to the cervix and lower portion of the uterus and sympathetic (T10-L1) provides sensory innervation to the fundus. ${ }^{18}$

Local anesthetics used prior to IUD insertion include a number of formulations (e.g., gel, injections and spray) and different techniques for administration (intracervical and paracervical). ${ }^{19-21}$ They have several advantages; however, no studies have provided strong evidence that various lidocaine formulations provide significant pain relief for women undergoing IUD insertion. ${ }^{4}$

Lidocaine has a rapid onset of action, reportedly around 2 minutes or less. ${ }^{22}$ As with duration of action, onset of action is liable to vary among application sites. We allowed 3 minutes to elapse between administration of lidocaine and IUD insertion, and based on the results, this time period was sufficient for the drug to take effect.

Our results showed significantly lower pain scores during tenaculum placement as compared with the placebo group $(\mathrm{p}=0.000)$ and sounding during IUD insertion in 
the lidocaine group as compared with the placebo group $(\mathrm{p}=0.000)$.

Oloto et al evaluated the efficacy of $2 \%$ lignocaine gel, inactive placebo gel or 'no treatment' applied to the cervical canal for reduction in pain in nulliparous or parous women. Intracervical application of $2 \%$ lignocaine gel resulted in a significant reduction in pain compared with no active treatment (placebo gel or no treatment; $\mathrm{p}=0.025){ }^{23}$ In contrast to Maguire et al study, Pain (measured by $100 \mathrm{~mm}$ VAS) was greatest during sounding and was similar between groups $(51.6 \mathrm{~mm}$ in the placebo group versus $55.5 \mathrm{~mm}$ in the lignocaine group; $\mathrm{p}=0.33$ ). Additionally, no significant difference between both groups for pain scores during IUD insertion $(\mathrm{p}=0.28){ }^{20}$

In McNicholas et al, study, no significant difference was observed between lidocaine and placebo gels at either of the time points studied for the overall participants, nor in the individual subgroups of nulliparous and parous women. The study groups did not differ significantly in median pain scores at tenaculum placement $(\mathrm{p}=0.54$ for nullipara and 0.23 for multipara) or during IUD insertion $\left(\mathrm{p}=0.18\right.$ for nullipara and 0.72 in multipara). ${ }^{19}$

Similar to present results, Torky et al reported that topical lidocaine gel and spray significantly reduce the pain induced by vulsellum application $(p=0.003)$ with no affection of the pain perception during IUD insertion $(p=0.059) .{ }^{24}$ However, they didn't assess neither the ease of insertion score rated by the insertion physician or the participants' satisfaction score. ${ }^{25}$

Fouda et al reported that the use of oral diclofenac potassium combined with $2 \%$ lidocaine gel slightly reduced pain scores during tenaculum application and IUD insertion. ${ }^{26}$ On the contrary, Abbas et al reported in their study on oral diclofenac potassium plus lidocaine cream significantly reduction of the VAS pain scores during injection of the dye and up to 30 minutes postprocedure with $\mathrm{p}=0.0001$. No significant differences in VAS score after speculum or tenaculum placement. ${ }^{27}$

Karasu et al reported that lidocaine spray is effective for reducing the pain experienced during IUD insertion. It reduces pain related to both tenaculum use $(\mathrm{p}<0.001)$ and IUD insertion $(p<0.001) .{ }^{28}$ However, in this study the researchers did not standardize all other confounding factors that could affect the effect of lidocaine on pain perception therefore, their results could be biased. ${ }^{29}$

The strengths of our study include that it was a doubleblind randomized controlled trial with neither women nor the clinicians being aware of the group assignment. The study had its limitations including that the study focused on one type of IUD because the levonorgestrel IUD is not widely used in Egypt due to its high cost, and consequently the data are applied only for the copper IUD. A second limitation was the subjectivity in reporting pain through VAS score, as there is no objective parameters t to evaluate pain. Furthermore, none of the included women were nulliparous because IUD insertion is not requested by this group in Egypt.

\section{CONCLUSION}

In conclusion, topical application of lidocaine gel on the cervix prior to copper T380A IUD insertion showed significantly lower pain scores only during tenaculum placement and sounding.

Funding: No funding sources

Conflict of interest: None declared

Ethical approval: The study was approved by the Institutional Ethics Committee

\section{REFERENCES}

1. Winner B, Peipert JF, Zhao Q, Buckel C, Madden T, Allsworth JE, et al. Effectiveness of long-acting reversible contraception. $\mathrm{N}$ Engl $\mathrm{J}$ Med. 2012;366:1998-2007.

2. United Nations Population Division. World Contraceptive Patterns 2013. Available at http://www.un.org/en/development/desa/population/ publications/pdf/family/worldContraceptivePatterns WallChart2013.pdf

3. Asker C, Stokes-Lampard H, Wilson S, Beavan J. What is it about intrauterine devices that women find unacceptable? Factors that make women non-users: a qualitative study. J Fam Plann Reprod Health Care. 2006;32:89-94.

4. Lopez LM, Bernholc A, Zeng Y, Allen RH, Bartz D, O'Brien PA, et al. Interventions for pain with intrauterine device insertion. Cochrane Database Syst Rev 2015;29;7:CD007373.

5. Abbas AM, Abdelkader AM, Elsayed AH, Adel S, Fahmy MS. Rectal indomethacin is an effective analgesic during copper T380A intrauterine device insertion: A randomized double-blind placebocontrolled trial. Glob J Reprod Med. 2017;2(1):555576.

6. Hubacher D, Reyes V, Lillo S, Zepeda A, Chen PL, Croxatto H. Pain from copper intrauterine device insertion: randomized trial of prophylactic ibuprofen. Am J Obstet Gynecol 2006;195:1272-7.

7. Khalaf M, Amin AF, Sayed Z, El-Nashar IM, Abbas AM. A randomized double-blind controlled trial of two different doses of self-administered vaginal misoprostol for successful copper intrauterine device insertion. Middle East Fertil Soc J. 2017; 22(4): 2648 .

8. Abdellah MS, Abbas AM, Hegazy AM, El-Nashar IM. Vaginal misoprostol prior to intrauterine device insertion in women delivered only by elective cesarean section: a randomized double-blind clinical trial. Contraception. 2017;95(6):538-43.

9. Abbas A, Ragb E, Khamis Y, Abdelkader A, Shaaban OM, Nasr A. Effect of cervical glyceryl 
trinitrate cream on pain perception during copper T380A intrauterine device insetion among parous women. Fertil Steril. 2017;108(3): e68.

10. Abbas AM, Abdellah MS, Khalaf M, Bahloul M, Abdellah NH, Ali MK, et al. Effect of cervical lidocaine-prilocaine cream on pain perception during copper T380A intrauterine device insertion among parous women: A randomized double-blind controlled trial. Contraception. 2017;95(3):251-6.

11. Abbas A, Ali MK, Abdalmageed OS, Yosef AH, Abdelkader AM, Shaaban OM. Evaluation of a novel uterine sound sparing approach for copper intrauterine device insertion. Fertil Steril. 2017;108(3):e123.

12. Elsedeek MS. Comparison between the traditional non-guided and a novel ultrasound-guided technique for office fitting of intrauterine contraceptive devices. Int J Gynaecol Obstet. 2016;133(3):338-41.

13. Ali MK, Abbas AM, Abdalmageed OS, Farghaly TA, Yosef AH. Classic versus uterine-sound sparing approach for insertion of copper T380A intrauterine device: Arandomized clinical trial. Middle East Fertil Soc J. 2017 (Article in press).

14. Abbas AM, Abdelkader AM, Elsayed AH, Fahmy MS. The effect of slow versus fast application of vulsellum on pain perception during copper intrauterine device insertion: A randomized controlled trial. Middle East Fertil Soc J. 2017 (Article in press).

15. Siderias J, Guadio F, Singer AJ. Comparison of topical anesthetics and lubricants prior to urethral catheterization in males: a randomized controlled trial. Acad Emerg Med. 2004;11(6):703-6.

16. Bouhassira D, Attal N, Alchaar H, Boureau F, Brochet B, Bruxelle $\mathrm{J}$ et al. Comparison of pain syndromes associated with nervous or somatic lesionsand development of a new neuropathic pain diagnostic questionnaire (DN4). Pain. 2005;14(12):29-36.

17. Scavuzzi A, Souza AS, Costa AA, Amorim MM. Misoprostol prior to inserting an intrauterine device in nulligravidas: a randomized clinical trial. Hum Reprod. 2013;28:2118-25.

18. Apte G, Nelson P, Brismée JM, Dedrick G, Justiz R, Sizer PS. Chronic female pelvic pain-part 1: clinical pathoanatomy and examination of the pelvic region. Pain Practice. 2012;12(2):88-110.

19. McNicholas CP, Madden T, Zhao Q, Secura G, Allsworth JE, Peipert JF. Cervical lidocaine for IUD insertional pain: a randomized controlled trial. Am J Obstet Gynecol 2012;207:384-6.
20. Maguire K, Davis A, Rosario TL, Westhoff C. Intracervical lidocaine gel for intrauterine device insertion: a randomized controlled trial. Contraception 2012;86:214-9.

21. Rapkin RB, Achilles SL, Schwarz EB, Meyn L, Cremer M, Boraas CM et al. Self-administered lidocaine gel for intrauterine device insertion in nulliparous women: a randomized controlled trial. Obstet Gynecol. 2016;128:621-8.

22. Gordh T. Lidocaine: the origin of a modern local anesthetic. 1949. Anesthesiology. 2010;113:1433-7.

23. Oloto EJ, Bromham DR, Murty JA. Pain and discomfort perception at IUD insertion effect of short-duration, low volume intracervical application of two percent lignocaine gel (InstillagelTM) a preliminary study. Br J Fam Plann. 1996;22:177180.

24. Torky H, Moussa A, El-Desouky ES, Dief O, Ahmed A. Lidocaine gel vs lidocaine spray in reducing pain during insertion of the intrauterine contraceptive device. Eur J Contracept Reprod Health Care. 2017;22(2):159-61.

25. Abbas AM. Comments on manuscript: Lidocaine gel vs lidocaine spray in reducing pain during insertion of the intrauterine contraceptive device. Eur $\mathrm{J}$ Contracept Reprod Health Care. 2017;22(5):398.

26. Fouda UM, Salah Eldin NM, Elsetohy KA, Tolba HA, Shaban MM, Sobh SM. Diclofenac plus lidocaine gel for pain relief during intrauterine device insertion. A randomized double blinded placebo-controlled study. Contraception. 2016;93(6):513-8.

27. Abbas AM, Wagdy WM, Salem MN, Abdelqader AM. Effect of oral diclofenac potassium plus cervical lidocaine cream on pain perception during hysterosalpingography: a randomized, double-blind, placebo-controlled trial. Middle East Fertil Soc J. 2017 (Article in press).

28. Karasu Y, Comert DK, Karadag B, Ergun Y. Lidocaine for pain control during intrauterine device insertion. J Obstet Gynaecol Res. 2017;43(6):1061-6.

29. Abbas AM. Comments on manuscript: Lidocaine for pain control during intrauterine device insertion. $\mathbf{J}$ Obstet Gynaecol Res. 2017 (Article in press).

Cite this article as: Abbas AM, Ragab E, Ali SS, Shady NW, Sallam HF, Sabra AM. Does lidocaine gel produce an effective analgesia prior to copper IUD insertion? Randomized clinical trial. Int J Reprod Contracept Obstet Gynecol 2018;7:806-10. 